\title{
Microbial colonisation of chasmoendolithic habitats in the hyper-arid zone of the Atacama Desert
}

\author{
J. DiRuggiero ${ }^{1}$, J. Wierzchos ${ }^{2}$, C. K. Robinson ${ }^{1}$, T. Souterre ${ }^{1}$, J. Ravel ${ }^{3}$, O. Artieda ${ }^{4}$, V. Souza-Egipsy ${ }^{5}$, and C. Ascaso ${ }^{2}$ \\ ${ }^{1}$ Biology Department, The Johns Hopkins University, Baltimore, MD, USA \\ ${ }^{2}$ Museo Nacional de Ciencias Naturales, MNCN - CSIC, 28006 Madrid, Spain \\ ${ }^{3}$ Institute for Genome Sciences, University of Maryland School of Medicine, Baltimore, MD, USA \\ ${ }^{4}$ Universidad de Extremadura, 10600 Plasencia, Spain \\ ${ }^{5}$ Instituto de Ciencias Agrarias, ICA - CSIC, 28006 Madrid, Spain
}

Correspondence to: J. DiRuggiero (jdiruggiero@jhu.edu)

Received: 2 October 2012 - Published in Biogeosciences Discuss.: 5 November 2012

Revised: 14 March 2013 - Accepted: 19 March 2013 - Published: 12 April 2013

\begin{abstract}
Efforts in searching for microbial life in the driest part of Atacama Desert, Chile, revealed a small number of lithic habitats that can be considered as environmental refuges for life. In this study, we describe for the first time chasmoendolithic colonisation of fissures and cracks of rhyolite-gypsum and calcite rocks collected in the hyperarid zone of the desert. The use of high-throughput sequencing revealed that the Atacama rock communities comprised a few dominant phylotypes and a number of less abundant taxa representing the majority of the total community diversity. The chasmoendolithic communities were dominated by Chroococcidiopsis species cyanobacteria and supported a number of heterotrophic bacterial lineages. Micro-climate data and geomorphic analysis of the mineral substrates suggested higher water availability in the calcite rocks in the form of enhanced water retention in the complex network of cracks and fissures of these rocks as well as increased occurrence of liquid water in the form of dewfall. These characteristics were associated with a diverse community of phototrophic and heterotrophic bacteria in the calcite chasmoendolithic ecosystem. This study is another example of the diversity of adaptive strategies at the limit for life and illustrates that rock colonisation is controlled by a complex set of factors.
\end{abstract}

\section{Introduction}

Under low moisture, thermal, and high solar radiation stress conditions, lithobiontic ecological niches found in deserts are considered environmental refuges for life (Friedmann, 1982; Pointing et al., 2009; Cary et al., 2010). Lithobiontic microorganisms can grow on the surface of rocks (epilithic), on the underside (hypolithic) and inside rocks (endolithic). The endolithic habitat can be subdivided into: (i) the cryptoendolithic habitat, consisting of natural pore spaces within the rock that are usually indirectly connected to the rock surface; (ii) the chasmoendolithic habitat, which are the fissures and cracks connected to the rock surface; (iii) the euendolithic habitat, which consists of channels and grooves formed in the rock by the metabolic activity of microorganisms (Golubic et al., 1981; Nienow, 2009; Wierzchos et al., 2012c); and (iv) the recently defined hypoendolithic habitat comprising the pore spaces located on the underside of the rock that makes contact with the underlying soil (Wierzchos et al., 2011; Vítek et al., 2013). In extremely arid deserts, microorganisms are mostly found inside translucent rocks, forming phototrophic-based endolithic communities with primary producers supporting a diversity of heterotrophic microorganisms (Walker and Pace, 2007a; Nienow, 2009). Endolithic habitats are known to provide microorganisms with a stable substrate, protection from intense solar radiation, temperature fluctuations, wind and desiccation, while allowing penetration of photosynthetically active radiation (PAR) for use by phototrophs (Friedmann and Ocampo-Friedmann, 1984; 
Walker and Pace, 2007a; Phoenix et al., 2006; Omelon, 2008; Nienow, 2009; Herrera et al., 2009). In contrast, surface soils under the same extreme environmental conditions do not support stable and functional microbial communities due to their physical instability, high porosity, low nutrient content and non-translucent properties (Pointing et al., 2009; Cary et al., 2010; Navarro-Gonzalez et al., 2003; Drees et al., 2006; Maier et al., 2003; Lester et al., 2007; Connon et al., 2007; Glavin et al., 2004).

The Atacama Desert, stretching 600 miles between the Pacific Coast of Northern Chile and the Andes mountains, is one of the oldest and driest deserts in the world. Sedimentary records indicate long periods of semi-arid to hyper-arid climates from the Jurassic (150 million years ago) to the present day, with extremely arid conditions arising in the Miocene (15 mya) (McKay et al., 2003; Dunai et al., 2005; Clarke, 2006; Hartley and Chong, 2002; Hartley et al., 2005). Its extreme aridity is the result of a constant climate regime produced by the Pacific Anticyclone, the Humboldt Current - an upwelling, cold current along the west coast of South America, and the rain shadow effect from the Andean Cordillera to the East (Hartley and Chong, 2002; Clarke, 2006). Between parallels $22^{\circ} \mathrm{S}$ and $26^{\circ} \mathrm{S}$ lies the hyper-arid zone of the Atacama, one of the places with the lowest pluviometric activity in the world (Dunai et al., 2005; Houston and Hartley, 2003; Miller, 1976). The Atacama Desert has been described as "the most barren region imaginable" (McKay et al., 2003), nevertheless, a long history of research in the desert has brought to light a range of habitats inhabited by microorganisms (Azua-Bustos et al., 2012; Wierzchos et al., 2012c). In the hyper-arid zone, only the deliquescence of ancient halite crusts of evaporitic origin have been shown to provide sufficient moisture to sustain photosynthetic activity (Wierzchos et al., 2006a, 2012b; de los Rios et al., 2010; Davila et al., 2008). Varnish on rocks' surfaces contained scarce quantities of cryptoendolithic bacteria (Kuhlman et al., 2008), whereas epilithic lichens (Wierzchos et al., 2011), endolithic cyanobacteria (Wierzchos et al., 2011; Dong et al., 2007) and endolithic algae and fungi (Wierzchos et al., 2011) were only found within evaporitic gypsum crusts in zones with higher air relative humidity. Recently, cryptoendolithic habitats for phototrophic cyanobacteria have been reported in volcanic ignimbrite rocks (Wierzchos et al., 2012a). Quartz substrates are also colonised by hypoendolithic microorganisms in other areas where fog and dew, rather than rain, constitute the main source of liquid water (Azúa-Bustos et al., 2011; Warren-Rhodes et al., 2006). Despite a great interest for endolithic communities, only a few large-scale molecular analyses of those habitats have been carried out (Pointing et al., 2009; Walker and Pace, 2007b).

Here, we describe the chasmoendolithic photosynthetic microbial communities associated with heterotrophic bacteria in two rock substrates from the Preandean Depression in the Atacama Desert: a volcanic rhyolite covered by gypsum crust collected in the proximity of the Tilocalar vol- cano, and a carbonate sedimentary rock from the Valle de la Luna formation. This study used a multiphasic approach that combined remote-sensing techniques, geological analyses, electron and photon microscopy investigations, and high throughput culture-independent molecular methods to fully characterise the microbial communities inhabiting these novel chasmoendolithic habitats and to identify potential factors driving their colonisation.

\section{Materials and methods}

The following is the summary of methods used in this study. More detailed information is provided in Supporting Information.

\subsection{Sampling and site characterisation}

Rhyolite rocks of volcanic origin were collected in 2010 in the Lomas de Tilocalar area and calcite rocks were collected in 2010 and 2011 near the Valle de la Luna area (Fig. S1). Microclimate data for Tilocalar was collected in situ from January 2010 to January 2012 using an Onset HOBO ${ }^{\circledR}$ Weather Station Data Logger (H21-001) as previously described (Wierzchos et al., 2012b). Microclimate data for Valle de la Luna were extracted from historical records for the village of San Pedro de Atacama located $5 \mathrm{~km}$ east of our sampling site.

\subsection{Mineralogy analyses}

The mineralogical composition of the Tilo and Luna rocks (ten samples for each site) was identified by X-ray powder diffraction. Quantitative determinations of major and minor elements of rhyolite and calcite rocks were carried out by X-ray fluorescence spectrometry. Chemical composition using X-ray fluorescence analysis was calculated with the $\mathrm{Na}_{2} \mathrm{O}+\mathrm{K}_{2} \mathrm{O}$ (wt \%) versus $\mathrm{SiO}_{2}$ (wt \%) diagram (Total Alkali Silica, TAS) (Lebas et al., 1986). Petrography studies were conducted on thin sections ( $30 \mu \mathrm{m}$-thick) of rhyolite and calcite rocks.

\subsection{Microscopy analyses}

Colonised rock samples were processed for scanning electron microscopy in backscattered electron mode (SEM-BSE) observation and/or energy dispersive X-ray spectroscopy (EDS) microanalysis according to a method introduced by Wierzchos and Ascaso (Wierzchos and Ascaso, 1994). SEMSE observations were carried out with small chips of rocks maintained in $100 \%$ relative humidity overnight before use. Fluorescence microscopy was performed on small chips of Luna rocks as previously described (Wierzchos et al., 2011). Transmission electron microscopy was carried out with rocks moistened with distilled water overnight before fixation. 
Table 1. Annual averages for climate data at Tilocalar (rhyolite) and Valle de la Luna (calcite) rocks.

\begin{tabular}{lcc|cc|c|cc|c|c}
\hline Sampling sites & \multicolumn{2}{c}{$\begin{array}{c}\text { PAR } \\
{\left[\mu \mathrm{mol} \text { photos }{ }^{-1} \mathrm{~m}^{-2}\right]}\end{array}$} & \multicolumn{2}{c|}{$\begin{array}{c}\text { Air Temp. } \\
{\left[{ }^{\circ} \mathrm{C}\right]}\end{array}$} & \multicolumn{2}{c|}{$\begin{array}{c}\text { Air Relative Humidity } \\
{[\%]}\end{array}$} & $\begin{array}{c}\text { Rainfall precipitation } \\
{[\mathrm{mm}]}\end{array}$ \\
\cline { 2 - 9 } & ave & high & low & ave & high & low & ave & high & ave \\
\hline Tilocalar $^{\mathrm{a}}$ & 599.7 & 2553.7 & -7.4 & 14.4 & 41.4 & 1 & 16.1 & 95.3 & $24.5(10)^{\mathrm{b}}$ \\
Valle de la Luna $^{\mathrm{c}}$ & - & $2600^{\mathrm{d}}$ & -1.8 & 13.1 & 32.2 & 16.7 & 40.5 & 80.9 & 27.8
\end{tabular}

Maximum (high), minimum (low) and average (ave) values for photosynthetic active radiation (PAR), $T$ and RH; ${ }^{\text {a }}$ data from 20 January 2010 to 20 January 2012 (this study); ${ }^{b}$ number of rainfall events in brackets; ${ }^{c}$ data for the village of San Pedro de Atacama located $5 \mathrm{~km}$ east of Valle de la Luna (see Supporting Information); d data for El Tatio geothermal field area located $66 \mathrm{~km}$ to the north from Valle de la Luna (Phoenix et al., 2006); “-” no data.

\subsection{DNA extraction, PCR-amplification and pyrosequencing of barcoded $16 \mathrm{~S}$ rRNA genes}

Total genomic DNA was extracted from rock powder using the PowerSoil DNA Isolation kit (MoBio Laboratories Inc., Solana Beach, CA) following the manufacturer's instructions. DNA was amplified using the barcoded universal primers $27 \mathrm{~F}$ and $338 \mathrm{R}$ for the V1-V2 hypervariable region. Amplicons from at least 3 amplification reactions were pooled together, purified and sequenced by 454 pyrosequencing using a Roche GS-FLX sequencing system (Roche-454 Life Sciences, Branford, CT).

\subsection{Processing of pyrosequencing data and statistical analysis}

Sequence processing and analysis was performed with CloVR-16S, which contains a series of tools for sequence analysis assembled into automated pipelines (Angiuoli et al., 2011) and Mothur (Schloss et al., 2009). To enable accurate estimates of species richness and diversity between samples (Lozupone et al., 2011), random subsets of all datasets simulating the same sequencing effort as for the Luna 1 sample (2622 sequences) were produced and re-analysed (Gilbert et al., 2009). Multiple alignments were built with reference to selected GenBank sequences using the Align tool in Greengenes (DeSantis et al., 2006) and blast analyses were carried out with the Blast tool in Greengenes (DeSantis et al., 2006).

All sequences were deposited at the National Center for Biotechnology Information Sequence Read Archive under accession numbers SRA052674, SRA052676, and SRA052675.

\section{Results}

\subsection{Microclimate data}

The area between the west slope of the central Andes and the east slope of the Coastal Cordillera, where our sampling sites were located (Fig. S1), exhibits a pronounced rain shadow effect, resulting in scarce precipitation between $15^{\circ} \mathrm{S}$ and $27^{\circ} \mathrm{S}$ (Houston and Hartley, 2003). We measured micro- environmental parameters during two years in the Tilocalar area and our data confirmed the occurrence of rare precipitations, a lack of fog and the absence of dewfall (moisture) on rock surfaces; we only detected moisture on rock surfaces during rainfalls and for a short time after a rain event (Table 1). Hyper-aridity is not only the result of a lack of rainfall precipitation $(P)$, it is also related to potential evapotranspiration (PET: mean annual potential evapotranspiration); a P/PET ratio (known as Aridity Index) of less than 0.05 is used to define the world's hyper-arid zones (Houston and Hartley, 2003). Taking into account the PET value of $2,920 \mathrm{~mm} \mathrm{yr}^{-1}$ from the nearby Salar de Atacama Basin (Houston, 2006) and rainfall precipitation values $(P)$ from Table 1, we calculated aridity indexes of $\sim 0.0085$ and $\sim 0.0095$ for Tilocalar and Valle de la Luna, respectively. These values indicated that the aridity in our sampling area was $\sim 5$ times higher than the aridity threshold for hyper-arid zones. More importantly, comparable evapotranspiration values and climate data obtained for Valle de la Luna from the weather station in San Pedro de Atacama, suggest that moisture conditions, i.e., air RH and rainfall, for the Tilo and Luna chasmoendolithic habitats were relatively similar (Table 1).

The photosynthetically active radiation (PAR) values were always very high for both sites with maximum between 2300 and $2600 \mu \mathrm{mol}$ photons $\mathrm{s}^{-1} \mathrm{~m}^{-2}$. The maximum temperature was recorded between 41 and $45^{\circ} \mathrm{C}$, which is slightly higher than temperatures reported in other parts of the Atacama hyper-arid zone (Wierzchos et al., 2011, 2012b).

The annual average relative humidity $(\mathrm{RH})$ in the area of Tilocalar was exceptionally low during the entire year (16.1\%; Table 1), with mean seasonal values of $7 \%$ and $10.8 \%$ in winter and spring of 2010 , respectively. The RH is significantly below the mean annual $\mathrm{RH}$ reported for some of the driest parts of the desert, such as Yungay (mean annual value of $34.75 \%$ ) (Wierzchos et al., 2012b). The rise of RH to $95 \%$ in Tilocalar was only observed during short rain events that occurred in 10 different episodes from January 2010 to January 2012, yielding $49 \mathrm{~mm}$ of rainfall for the two years, and separated by large periods of time. Electrical conductivity sensors in the field indicated that almost all the moisture deposition events were directly related to rainfall episodes, suggesting that the moistening of the rhyolite rock 
surface was the result of precipitation rather than water condensation (dew formation). Recorded average annual values of RH for San Pedro de Atacama, located $5 \mathrm{~km}$ east of Valle de la Luna (40.5\%; Table 1), was remarkably higher than in Tilocalar, potentially enhancing dew formation on the calcite rock surfaces in Valle de la Luna. This might be due to the proximity of Salar de Atacama's small ponds.

\subsection{Physical and chemical characterisation of chasmoendolithic microbial habitats}

According to X-ray diffraction analyses, samples from a rhyolitic volcanic boulder collected in Tilocalar were composed of quartz (tridymite and cristobalite), biotite, plagioclase (andesine) and microcline. In this paper, we will refer to these rhyolithic rocks as the "Tilo" rocks. X-ray fluorescence analysis confirmed the rhyolithic composition of the rocks with $3.92 \% \mathrm{Na}_{2} \mathrm{O}, 4.44 \% \mathrm{~K}_{2} \mathrm{O}$ and $70.69 \% \mathrm{SiO}_{2}$. These rocks exhibited cracks and pores filled with gypsum and areas where the rhyolite surface was covered with gypsum efflorescence (Fig. 1a and b) forming blisters and a crust $2-5 \mathrm{~mm}$ thick. Because we also found gypsum crystals inside pores and spaces deep inside the rocks, where we did not find microbial cells, it is likely that the origin of the gypsum deposits is associated with hydrothermal alteration, water-magma reactions, volcanic fluids or phreatic waters (Ohba and Nakagawa, 2002) rather than bio-mineralisation. Furthermore, gypsum bio-mineralisation has been described in environments with abundant liquid water (Petrash et al., 2012), but never in hyper-arid environments. Detailed examination of the rhyolite rock surfaces revealed microbial colonisation within the gypsum surface crust and at the contact zone between the gypsum crust and the rhyolite rock surface (Fig. 1a). This endolithic colonisation was visible as a narrow $0.2-1 \mathrm{~mm}$ thin, pale green layer (Fig. 1a). The rocks micromorphology, examined by scanning electron microscopy in backscattered electron mode (SEM-BSE), showed fissures and cracks inside the rhyolite with some fissures also filled with gypsum, as confirmed by energy dispersive X-ray spectroscopy (EDS) elements distribution maps (Fig. 1b). Further analyses (SEM-BSE-EDS) revealed the distribution of gypsum (yellow spots of $\mathrm{Ca}$ and $\mathrm{S}$ belonging to $\mathrm{CaSO}_{4} \times 2 \mathrm{H}_{2} \mathrm{O}$ ) inside the rhyolite fissures and pores (Fig. 1b) and on the surface crust covering the rhyolite.

Microbial cell aggregates detected by SEM-BSE were not numerous but were uniformly distributed across the contact zone between mineral grains (Fig. 1b-e). Cell-forming aggregates with morphology similar to cyanobacteria of the Chroococcales were tightly packed in the rock's fissures among gypsum crystals (Fig. 1c). Morphologically similar cyanobacterial cells were also found in fissure and crack spaces with gypsum crystals and cristobalite (Fig. 1d) as well as gypsum and plagioclase (Fig. 1e). Observations of microbial colonisation from the same areas with fluorescence microscopy revealed autofluorescence of cyanobacterial cells

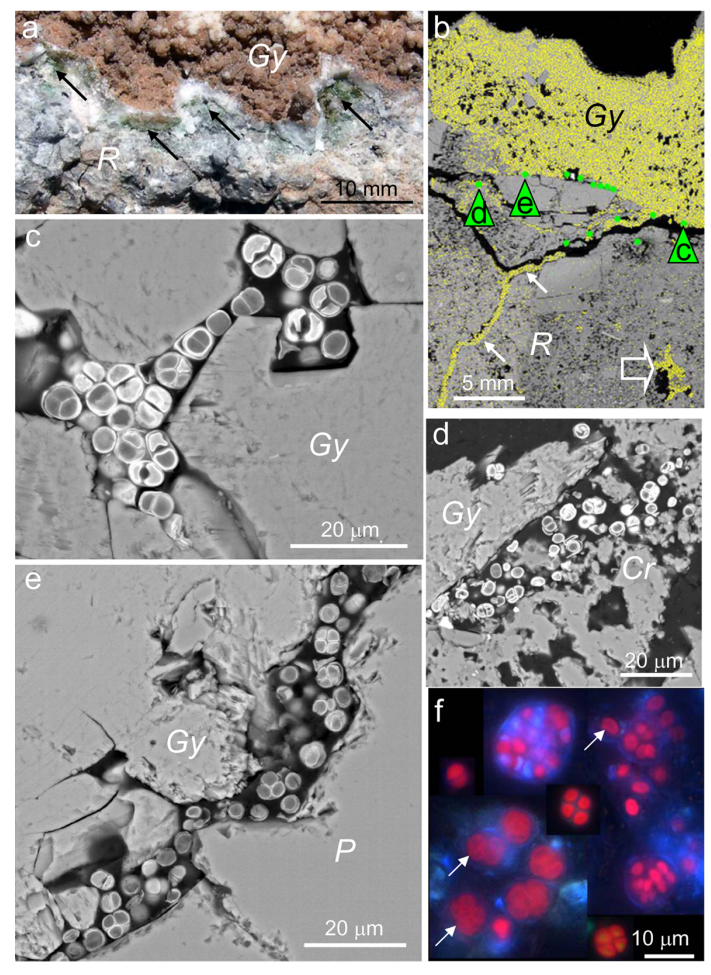

Fig. 1. Cross-sections of Tilo rhyolite rocks and their microbial colonisation. (a) In field macroscopic view of rhyolite $(R)$ revealing green spots of chasmoendolithic microorganisms (black arrows) beneath gypsum (Gy) deposits. (b) SEM-BSE low magnification image of transversal section showing gypsum deposit (Gy) covering rhyolite $(R)$ rock. Gypsum deposit composition and gypsum occurrence within fissures (white arrows) and pore (open arrow) were detected by superpositioned image (yellow spots) of Ca and $\mathrm{S}$ (belonging to $\mathrm{CaSO}_{4} \times 2 \mathrm{H}_{2} \mathrm{O}$ ) and obtained by EDS elemental distribution map. Green dots show places where chasmoendolithic microorganism cells where detected and arrowheads indicate position of the cells showed in following (c-e) SEM-BSE detailed images. (c) SEM-BSE image of cyanobacteria cell aggregates within fissures among gypsum $(G y)$ crystals. (d) SEM-BSE image of cyanobacteria cells within fissures among cristobalite $(C r)$ matrix. (e) SEM-BSE image of cyanobacteria cells within fissures between gypsum $(G y)$ and plagioclase $(P)$ crystals. (f) Fluorescence microscopy image of cyanobacteria (red autofluorescence) cell aggregates isolated from rock; some of the cells reveal autofluorescent concentric thylakoidslike structures (white arrows). Blue signal is autofluorescence of dead cells or their relics and extracellular polymeric substances.

(Fig. 1f). Both SEM-BSE and fluorescence microscopy documented the similar morphology between the cyanobacterial cells and those of the Chroococcidiopsis genus (Fig. 1f). A schematic diagram of the rhyolite microbial colonisation is showed in Fig. 3a.

Rock samples from Valle de la Luna were composed of laminated calcite layers with a thickness of several centimetres (Fig. 2a). The calcite composition of these layers was confirmed by X-ray diffraction analysis, with some of the 
layers interspaced with limestone. In this paper, we refer to these calcite rock layers as "Luna" rocks. Petrographic study showed sparitic and microsparitic crystals of calcite, forming undulated sheets (data not shown). The bottom and top of these layers (clear brown color in the field, Fig. 2a) were composed of ooids and some detrital grains of quartz cemented by sparitic calcite crystals, forming hardened layers. This hardened cover, up to $5 \mathrm{~mm}$ thick, formed an impermeable layer in which pores and fissures of the original rock were infilled with secondary calcite. This calcite had most probably precipitated from outward migration in solution. Many of the calcite layers showed fragmentation in the form of irregular narrow cracks that extended perpendicular or parallel to the rock surface (Fig. 2a and b). This type of weathering has been attributed primarily to repeated expansion and contraction induced by extreme diurnal rock temperature variations. However, concomitant action of other mechanisms such as wetting/drying, salt crystallisation/solution, salt hydration/dehydration, and freeze/thaw cycles before breakdown can also produce the same type of weathering (Smith, 1988). Detailed studies of the surface of calcite layers frequently show the presence of micro-scale weathering features, defined as microrills or "rillensteine" (Fig. 3c), and forming small and short sinuous channels (normally $<1 \mathrm{~mm}$ wide and deep) and flutelike features (Smith, 1988).

An abundant microbial colonisation of cracks and fissures, in the form of green and green-yellow spots, was almost always found upon fracturing the rocks with a hammer (Fig. 2a). The rock colonisation was close to the surface and as deep as $20-30 \mathrm{~mm}$ (Fig. 2a). Dense cellular aggregates were found in a well-developed network of cracks and fissures within the calcite layers (Fig. 2b and c). A higher magnification view of these microbial aggregates revealed the presence of cells with morphology similar to cyanobacteria from the Chroococcales order (Cy) and a relatively large amount of heterotrophic bacterial cells (Fig. 2d). The 3-D reconstruction of fluorescence microscopy images displayed the intense autofluorescence of phototrophic cells (red) associated with SYBR Green-stained heterotrophic bacterial cells (green signal in Fig. 2e). The close association between phototrophs and heterotrophs can also be observed using SEMSE (Fig. 2f). The abundance of biological material within the Luna rocks permitted their isolation and observation with TEM, which was not possible with the Tilo rocks. Single baeocytes of cyanobacteria from the Chroococcales order were visualised, revealing ultrastructural elements such as cellular granules and thylakoid intracytoplasmic photosynthetic membranes (Fig. S2a). Our microscopic observations confirmed the similar morphology between the observed cyanobacteria cells and members of the Chroococcidiopsis genus (Fig. S2a-c). The TEM images showed cyanobacterial cells surrounded by electron dense structures forming several concentric sheaths and abundant extracellular material (Fig. S2b and c). Several areas of this dense biofilm also revealed heterotrophic bacteria embedded within the extracel-

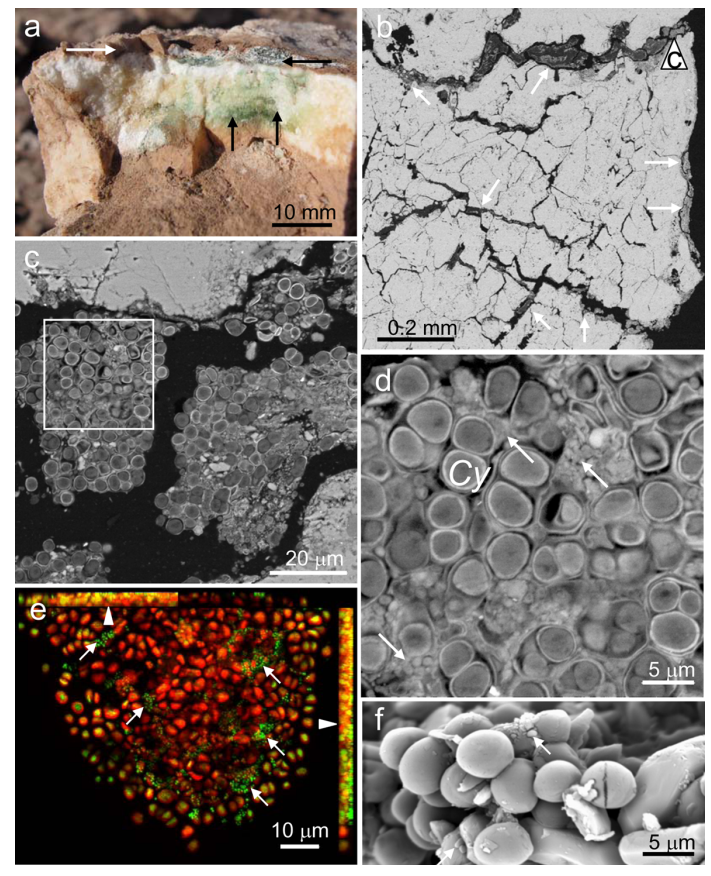

Fig. 2. Cross-sections of Luna calcite rocks and their microbial colonisation. (a) In field macroscopic view of calcite fissure wall revealing green spots of chasmoendolithic microorganisms (black arrows) beneath the rock surface. Note the presence of a hardened surface layer (white arrow) with microrills. (b) SEM-BSE low magnification image of transversal section showing the fissure and crack network within calcite rock; white arrows shows places where aggregates of chasmoendolithic microorganism cells where detected and the arrowhead indicates the position of the cells showed in (c) and (d). (c) SEM-BSE image of cyanobacteria cell aggregates within a thick fissure. (d) Detailed SEM-BSE image from square area in (c) of cyanobacteria cells $(C y)$ associated with heterotrophic bacteria cells (arrows). (e) In situ fluorescence microscopy image (3-D reconstruction) of SYBR Green I stained chasmoendolithic microorganisms within the calcite rock obtained by SIM technique showing an undisturbed aggregate of cyanobacteria (red autofluorescence) and associated heterotrophic bacteria (green SBI signal); arrowheads point to lateral projections of the image. (f) SEM-SE image of external morphology of cyanobacteria cells with associated heterotrophic bacteria (arrows).

lular material attached to the cyanobacterial cells (Fig. S2c and d). A schematic diagram of the calcite microbial colonisation is shown in Fig. 3b.

\subsection{Molecular characterisation of rock microbial communities}

The endolithic communities of Tilo and Luna rocks were characterised by high-throughput sequencing of barcoded 16S rRNA gene sequences. We performed DNA extractions from two Luna rocks (Luna 1 and Luna 2), collected within $50 \mathrm{~m}$ of each other, and from one Tilo sample consisting of several rock fragments collected over a $1 \mathrm{~m}^{2}$ area (Tilo). 
Amplicons pooled from triplicate 16S rRNA gene amplifications were sequenced by pyrosequencing. We obtained a total of 17032 high quality sequence reads from three dataset with 2622, 3715 and 10695 reads for Luna1, Luna2 and Tilo, respectively. To remove biases from sequencing efforts, each sample was randomly sub-sampled to obtain datasets equivalent to those from the sample with the lowest sequence read count (Luna Rock 1:2622 sequence reads) as recommended by Lozupone et al. (2011). Operational taxonomic units (OTUs) assignment at the $95 \%$ sequence similarity level was performed with CloVR-16S on the sub-sampled dataset (Table S1) (Angiuoli et al., 2011). We validated our analysis of $\beta$-diversity (communities comparison) by calculating pairwise UniFrac metrics for our 3 datasets (Luna 1 and 2, and Tilo) (Lozupone et al., 2006). We applied the UniFrac significance test to our pairwise comparisons and the reported p-values indicated that the two replicate samples from Valle de la Luna (Luna 1 and 2) shared significantly similar lineages ( $p$ values corrected for multiple comparison using the Bonferroni correction $=1$ ), whereas, the sample from Tilocalar (Tilo) was significantly different from the two samples from Valle de la Luna ( $p$ values were $<0.04$ and $<0.01$ for the two comparisons, respectively). Non-metric multidimensional scaling of Theta-YC distances, based on relative abundance of OTUs, also showed a clear clustering of the two Luna communities away from the Tilo community (Schloss et al., 2009; Yue and Clayton, 2006); analysis of molecular variance on the distances was highly significant with a $p$ value $<0.001$ (Schloss et al., 2009).

Of the 382 OTUs ( $95 \%$ sequence similarity level) obtained for the Luna and Tilo rocks, $\sim 50 \%$ were represented by a single sequence (singletons) and only 30 OTUs were shared between the Tilo and Luna communities; in contrast, 88 OTUs were shared between the two Luna rocks (Fig. S3). More than $93 \%$ of OTUs could be classified at the phylum level (using the RDP Classifier trained using the Greengenes reference database) and $89 \%$ and $76 \%$ of the Tilo and Luna rocks, respectively, at the family level, indicating a number of unknown lineages (Fig. 4a). Good's coverage is an estimator of sampling completeness and calculates the probability that a randomly selected amplicon sequence from a sample has already been sequenced. At the $95 \%$ similarity level, we had $98 \%$ coverage for the Luna rocks and $96 \%$ for the Tilo rocks (Table 2).

Both rock communities were dominated by a few highly abundant OTUs (those containing $>1 \%$ of total sequences) that represented $\sim 79 \%$ of the sequences (22 OTUs for Luna Rocks and 6 OTUs for Tilo Rocks). The most abundant OTUs in the Tilo communities were members of the phylum Cyanobacteria and the class Gammaproteobacteria, whereas those in the Luna community belonged to the phyla Cyanobacteria, Actinobacteria, Proteobacteria, Deinococcus-Thermus, Bacteroidetes and Gemmatimonadetes (Fig. $4 \mathrm{a})$. The remaining sequences $(\sim 21 \%)$ comprised 93 singletons in the Tilo community but only 56 in

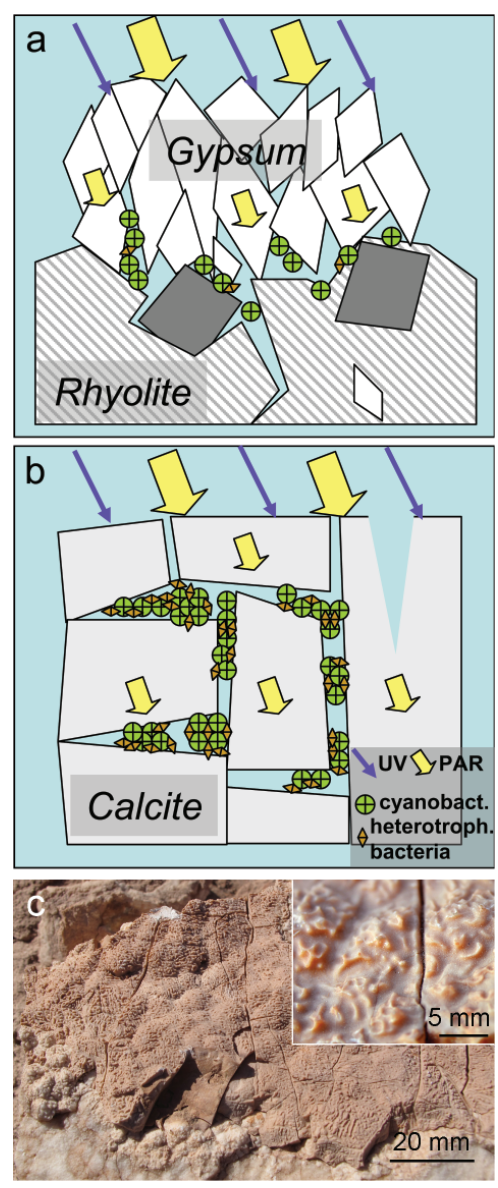

Fig. 3. Scheme illustrating the physical properties of the Tilo and Luna rock substrates and the topology of the chasmoendolithic colonisation. (a) In rocks from the Tilocalar area, the microorganisms are localised between the gypsum deposits and rhyolite rock, up to $5 \mathrm{~mm}$ deep, affording little space for water retention. (b) The network of crack and fissures, up to $30 \mathrm{~mm}$ deep, of calcite rocks from Valle de la Luna provide ample space of colonisation and water retention. Both rock substrates protect microorganisms from the deleterious effect of UV radiation while allowing enough PAR through for photosynthetic activity. Drawings are on different scales. (c) Surface of calcite bed from Valle de la Luna showing microrill (rillensteine) weathering features. Insert image shows a detailed view of these calcite dissolution structures; note the irregularly fractured limestone hardened layer.

the Luna communities (Fig. S4). It was intriguing to find a large number of OTUs in the Tilo community that belonged to the Burkholderiaceae family (Fig. 4a). However, Burkholderia are ubiquitous, they are found in soil, ground water and they have been previously detected in rock varnish communities from the Atacama Desert (Kuhlman et al., 2008). In all, 8 to 11 phyla (phyla with more than one representative OTU), out of the $\sim 75$ known bacterial phyla (Ley et al., 2006), were represented in the rock communities. No Archaea were found in any of the samples despite multiple attempts at PCR amplification using specific ar- 


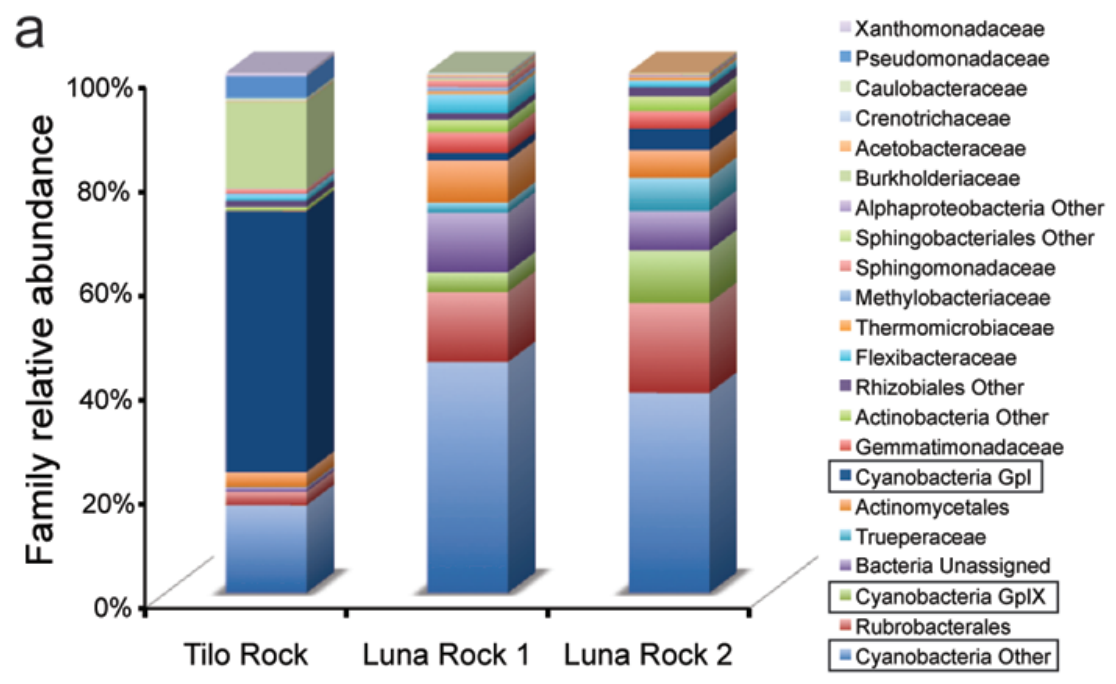

b
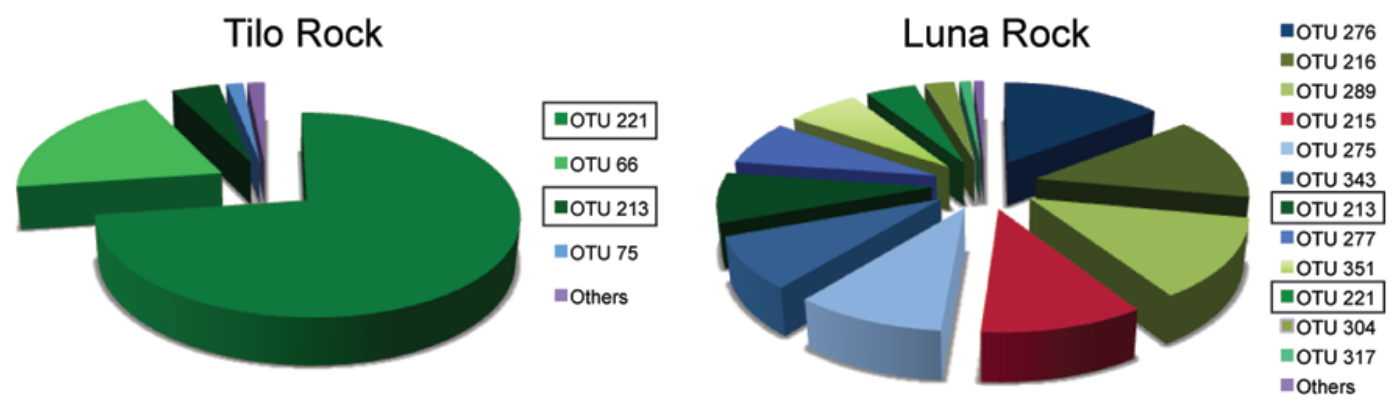

Fig. 4. Atacama rock community structure based on environmental 16S rRNA gene sequences from the Tilo and Luna rocks. (a) Relative abundance of major bacterial families (> 10 counts summed across all samples); "other" are unidentified bacterial lineages; boxes are cyanobacterial families. (b) Relative abundance of Cyanobacteria OTUs ( $>5 \%$ cut off); boxes are common OTUs. Taxonomic assignments according to Table S2: green colours are Pleurocapsales (Chroococcidiopsis), blue colours are Nostocales, the colour red is Oscillatoriales, and the colour purple is "others" (taxa represented by $<1 \%$ ). Analysis based on equally sized datasets (2622 sequence reads), randomly sub-sampled from Tilo and Luna Rock datasets.

chaeal primers [4Fa and 338R (Lane, 1991)] with and without nested primers (data not shown).

The most abundant shared OTUs between the two communities belonged to the phyla Cyanobacteria and Actinobacteria, as well ad the class Alphaproteobacteria (Fig. 4). Diversity estimates (a combination of the richness and evenness of a community), as reported by the Shannon and Simpson indexes (Table 2), showed greater diversity for the Luna than the Tilo community, irrespective of a similar richness between the communities. This is likely the result of the large number of singletons found in the Tilo community resulting in a greatly uneven phylotype distribution (Fig. S4). Measurements of $\beta$-diversity, using the UniFrac $t$ test (Lozupone et al., 2006) and non-metric multidimensional scaling of Theta-YC distances (Schloss et al., 2009) as described above, indicated that overall composition of the two communities differed significantly from each other.
While both communities were dominated by oxygenic photosynthetic cyanobacteria, phototrophs represented $71 \%$ of the total bacterial taxa in the Tilo rocks but only $50 \%$ in the Luna rocks (Fig. 4). In the Tilo rock community, the majority of cyanobacteria were assigned to the genus Chroococcidiopsis (97\%) (Pleurocapsales order) and only one phylotype was assigned to the Nostocales (Fig. 4b). The Luna cyanobacterial community also displayed a large number of Chroococcidiopsis phylotypes (49\%), but it was more diverse, with sequences related to members of the Nostocales and Oscillatoriales (Fig. 4b; Table S2). Blast analysis of sequences representative of phototrophs from the Tilo and Luna communities showed that they were most closely related to environmental sequences from endolithic and hypolithic habitats from extreme deserts around the world (Table S2). 
Table 2. Observed richness, diversity indexes and sequence coverage for the Tilo and Luna rocks based on 16S rRNA gene sequence assignments with a $95 \%$ sequence similarity threshold.

\begin{tabular}{lcccc}
\hline Samples & $\begin{array}{c}\text { OTUs }^{\mathrm{a}} \\
\text { Observed } \\
\text { richness }\end{array}$ & $\begin{array}{c}\text { Shannon index } \\
\text { Estimated } \\
\text { diversity }\end{array}$ & $\begin{array}{c}\text { Inverse Simpson } \\
\text { index }^{\mathrm{a}} \\
\text { Estimated diversity }\end{array}$ & $\begin{array}{c}\text { Good's } \\
\text { Coverage } \\
\%\end{array}$ \\
\hline Tilo & 173 & 2.2 & 3.75 & 96 \\
Luna 1 & 175 & 3.8 & 26.14 & 98 \\
Luna 2 & 152 & 3.6 & 21.40 & 98 \\
\hline
\end{tabular}

Abbreviation: OTU, operational taxonomic units; ${ }^{\mathrm{a}}$ analysis using datasets of equal size (2622 sequence reads), subsampled from for all Tilo and Luna rock samples.

\section{Discussion}

\subsection{Microclimatic and physical differences in the chasmoendolithic microbial colonisation of rhyolite-gypsum and calcite rocks}

Efforts in searching for microbial life in the hyper-arid zone of the Atacama Desert recently revealed a small number of lithic habitats colonised by phototrophy-based communities (Dong et al., 2007; Warren-Rhodes et al., 2007; Azúa-Bustos et al., 2011; de los Rios et al., 2010; Wierzchos et al., 2006a, 2011, 2012a; Kuhlman et al., 2008). Most of these habitats were cryptoendolithic and a small number were hypoendolithic. Here, we describe novel chasmoendolithic microbial ecosystems within calcite rocks and within the mineral phase between volcanic rhyolite and gypsum crust in two geographic locations of the Atacama Desert subjected to similar hyper-arid environmental conditions.

Distribution of the chasmoendolithic colonisation in the Atacama rocks was significantly different between the two rock substrates we compared. Colonisation in the rhyolite rock was localised in direct contact or in close proximity to the gypsum $\left(\mathrm{CaSO}_{4} \times 2 \mathrm{H}_{2} \mathrm{O}\right)$ mineral phase; cyanobacterial cells were uniformly distributed within the rock fissures among gypsum crystals, the plagioclase and cristobalite minerals, and their combination (e.g., fissure among gypsum and cristobalite). In contrast, colonisation of the Valle de la Luna rock was found along networks of deep cracks and fissures of almost pure calcite $\left(\mathrm{CaCO}_{3}\right)$. Differences in mineralogy and porosity between basaltic glasses and obsidian rocks colonised by endolithic bacteria were suggested as potential factors influencing microbial community structure and composition (Cockell et al., 2011). Similarly, the fine-grained gypsum crusts of the Atacama and Mojave Deserts harbored abundant colonisation of heterotrophic bacteria whereas very few were found in the fibrous gypsum from the Jordan Desert (Dong et al., 2007). It is, therefore, likely that the physical and chemical properties of the substrates influence the bioreceptivity of the Tilo and Luna rocks.

The effectiveness of gypsum $\left(\mathrm{CaSO}_{4} \times 2 \mathrm{H}_{2} \mathrm{O}\right)$ in attenuating UV light has been reported in several studies suggesting that in the rhyolite rock covered by gypsum, $\mathrm{CaSO}_{4} \times 2 \mathrm{H}_{2} \mathrm{O}$ provides protection against harmful UV radiation. Amaral et al. (2007) reported transmission of less than $20 \%$ of UV light through a $0.5 \mathrm{~mm}$-thick gypsum layer and significant attenuation of UV radiation was shown with Arctic and Antarctic gypsum crusts of $\sim 1 \mathrm{~mm}$ thick (Cockell et al., 2010; Hughes and Lawley, 2003). A similar mechanism of light scattering was suggested to explain the UV protective effect of both gypsum and calcite $\left(\mathrm{CaCO}_{3}\right)($ Cockell and Raven, 2004; Cockell et al., 2008). While UV is almost completely attenuated by a $1.2 \mathrm{~mm}$ thick layer of gypsum $(0.005 \%$ of UVB and $0.05 \%$ of UVA remaining), the decline in visible light transmission occurs at a much lower rate (PAR transmission remaining $\sim 1 \%$ ), providing sufficient photosynthetically active radiation for phototrophs (Hughes and Lawley, 2003; Amaral et al., 2007). Light penetration studies in dolomite $\left[\mathrm{CaMg}\left(\mathrm{CO}_{3}\right)_{2}\right]$ from Switzerland reported up to $5 \%$ of light surface intensity still present at 2 to $3 \mathrm{~mm}$ within the rock, providing a perpendicular incidence (Horath et al., 2006). In limestone $\left(\mathrm{CaCO}_{3}\right)$ of the Niagara Escarpment, phototrophic colonisation of the rock extended between 0.9 and $3.5 \mathrm{~mm}$ deep (Matthes et al., 2001), where only a fraction of the surface light was detectable, suggesting that light attenuation patterns might limit the depth distribution of algae and cyanobacteria within the rock (Matthes et al., 2001; Horath and Bachofen, 2009). We showed that chasmoendolithic phototrophs from the calcite rock of Valle de la Luna colonised a network of fissures 20 to $30 \mathrm{~mm}$ deep without forming a clear inner boundary within the rock. This colonisation pattern might suggest that fissures increase the amount of light available within the rock, allowing chasmoendolithic phototrophs to penetrate deeper inside the rock. Water-filled fissures below the rock surface have even been suggested to act as optic glass fibers, conducting light inward and deeper inside the rock (Danin, 1999). Schematics of chasmoendolithic microbial ecosystems in semi-translucent calcite and in gypsum crust associated with rhyolite (Fig. 3) illustrate the remarkable properties of both rock substrates for limiting exposure to UV radiation and potential photo-inhibition while providing enough light for photosynthesis.

One factor that might relate to the more diverse community observed in the calcite chasmoendoliths is physical stability of this substrate. Calcite shows very low solubility rates $\left(0.015 \mathrm{~g} \mathrm{~L}^{-1} ; K_{\mathrm{SP}}=4.8 \times 10^{-9}\right)$ when compared to gypsum $\left(2.4 \mathrm{~g} \mathrm{~L}^{-1} ; K_{\mathrm{SP}}=3.14 \times 10^{-5}\right)$. Gypsum saturated water solution has a specific conductance value of $2.2 \mathrm{~d} \mathrm{~m}^{-1}$ compared to only $0.03 \mathrm{~d} \mathrm{~m}^{-1}$ for a saturated solution in equilibrium with calcite, producing an aqueous solution with a much higher osmotic pressure in the rhyolite-gypsum substrate than in the calcite rock and potentially resulting in osmotic stress for members of the community. Corbel (Corbel, 1971) deduced that solution rates of limestone from arid western Algeria were equivalent to surface lowering of

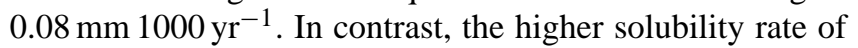
gypsum crystals would decrease substrate stability and might 
deeply affect the diversity and survival of microorganisms within this substrate.

Although we did not collect experimental data on rock surface-moisture for Valle de la Luna, we speculate that the occurrence of dew on the calcite rock is likely because of its high thermal conductivity (TC) of 3.25 to $3.90 \mathrm{~W} \mathrm{~m}^{-1} \mathrm{~K}^{-1}$. The thermal conductivity of gypsum is twenty times lower (TC of $0.17 \mathrm{~W} \mathrm{~m}^{-1} \mathrm{~K}^{-1}$ ). This is important, because it is commonly accepted that dewfall can be a substantial source of moisture in many of the world's deserts (Büdel et al., 2008; Kappen et al., 1979; Kidron, 2000, 1999). Microrills features, attributed to calcite dissolution induced by the presence of thin films of water from dew, have been reported for limestones from the southeast desert in Morocco (Smith, 1988; Laudermilk and Woodford, 1932). According to the solution rates of limestone reported by Corbel (1971), the $1 \mathrm{~mm}$-deep microrills we observed in Valle de la Luna would require $\sim 12500$ yr to be shaped by moisture events, strongly supporting the persistence of climatic conditions over long periods of time in this region. Dewfall episodes were also indicated as important factors involved in the formation of microkarstic features in deserts (Smith, 1988) that were found associated with endolithic and epilithic algae responsible for algal boring, plucking and etching (Smith et al., 2000). The high thermal conductivity of calcite, higher air RH values, and the characteristic microkarstic features found on the calcite layer surfaces strongly suggest that dewfall might be a common and important source of liquid water for the chasmoendolithic community inhabiting the calcite rock of Valle de la Luna, greatly increasing water availability in this ecosystem.

Colonisation zone in the Tilo rock was located beneath a $2-5 \mathrm{~mm}$ thick layer of gypsum covering the poorly porous rhyolite rock (mercury intrusion porosimetry, data not show). In this chasmoendolithic habitat, water evaporation rates after scarce rainfalls would be relatively high. In contrast, the Luna rock fissures were abundant, narrow and deep (up to 20-30 mm), perpendicular and also parallel to the rock surface, forming a complex labyrinth-like network. Liquid water storage and its retention would be high in this type of fissures and cracks network, suggesting higher water availability in the calcite rock, possibly affecting the microbial diversity we observed in the chasmoendoliths of the Luna rock.

\subsection{Microbial composition in rocks from the hyper-arid zone of the Atacama}

We used high-throughput sequencing for an in-depth characterisation of microbial communities inhabiting rock formations in the hyper arid zone of the Atacama Desert. This area is particularly inhospitable and colonised rocks in Tilocalar (rhyolite covered by gypsum crust) and Valle de la Luna (calcite) were extremely scarce. Two independent rock samples from Valle de la Luna were analysed. From Tilocalar, because of the paucity of colonised rocks and the small size of each colonised zone, material from several rocks collected over $1 \mathrm{~m}^{2}$ was pooler for DNA extraction. Statistical analysis of microbial community composition showed low intrasite variation for Valle de la Luna and a significant difference between the Valle de la Luna and Tilocalar sites. Our data also showed that the Tilo and Luna rock communities follow an environmental community model consisting of a few dominant phylotypes and a number of less abundant taxa that constituted the majority of the total community diversity (Sogin et al., 2006).

Analysis of the microbial communities inhabiting the rhyolite-gypsum and calcite rocks uncovered substantial bacterial diversity and significant differences in community structure and composition between the two types of substrates. The absence of amplicons when using archaealspecific primers and our detailed observations with several microscopy techniques (SEM-BSE, SEM-SE, TEM, and FE) strongly suggest that these communities were uniquely bacterial. The calcite rock community was characterised by a higher diversity than that of the rhyolite-gypsum rock, as calculated by diversity estimators. While both communities were dominated by cyanobacteria of the Chroococcidiopsis genus that are typically found in endolithic (de los Rios et al., 2010; Wierzchos et al., 2006b, 2012a; Pointing et al., 2009; Dong et al., 2007; Wong et al., 2010) and hypolithic habitats (Warren-Rhodes et al., 2006; Azúa-Bustos et al., 2011) of extremely cold and hot deserts, phototrophs in the Luna rock were more diverse, including members of the Nostocales and Oscillatoriales families. Associated with phototrophs, endolithic communities also harbour heterotrophic microorganisms, which are mostly consumers and derive their energy from the products of photosynthesis (Friedmann and Ocampo-Friedmann, 1984). Remarkably, the associated heterotrophs of the Atacama chasmoendolithic communities also differed with rock types. Heterotrophic bacteria represented a larger fraction of the community in the Luna rock and were found embedded in extracellular matrix. The most common phylotypes in the Luna community, in addition to cyanobacteria, belong to phyla that are commonly found in endolithic habitats (Dong et al., 2007; de la Torre et al., 2003; Walker and Pace, 2007b; Pointing et al., 2009; Wong et al., 2010), in contrast, the Tilo community was mostly dominated by cyanobacteria.

\section{Conclusions}

This study reports for the first time on chasmoendolithic microbial communities in lithic substrates of the hyper-arid zone of the Atacama Desert. We describe here relatively simple microbial communities inhabiting the cracks and fissures of calcite and rhyolite-gypsum rocks. These communities were dominated by desiccation-tolerant cyanobacteria associated with microorganisms found in other endolithic habitats worldwide, supporting the hypothesis put forward 
by Walker and Pace (Walker and Pace, 2007a) of a global meta-community uniquely adapted to the endolithic habitat. Under the extreme environmental conditions of the Atacama Desert, we suggest that these chasmoendolithic habitats protect microbial communities from UV and excessive PAR radiation and supply increased moisture, thus, providing environmental refuges - or islands of life - in the desert. While the rock mineralogy and physical stability of the substrate are important factors, water availability appeared to be essential in shaping these endolithic microbial communities. In Valle de la Luna, the occurrence of liquid water in the form of scarce precipitations and potential dewfalls, and the increased water retention facilitated by the pervasive network of cracks and fissures in the rock, were associated with a significantly more diverse microbial ecosystem. However, water is likely not the only factor shaping these communities. Rock substrates are typically considered low-nutrient environments and the effects of the rock's mineral composition on microbial communities should not be ignored. This question might be best addressed by investigating the mineral-cell interface for evidence of mineral transformation and by using expression profiling of communities to address directly their physiology. The chemical composition of the substrate also affects light transmission, possibly modulating the photosynthetic component of the community. Measurements of photosynthetic activity across a range of substrates, under similar climatic conditions, might provide answers to this question. Finally, interactions between members of the community, in particular primary producers and heterotrophs, and the presence of viruses, are likely important factors that should also be addressed. Field studies on community primary productivity coupled with expression profiling under diurnal, seasonal and water stress might provide the information needed to understand better the functioning of these ecosystems and the factors driving substrate colonisation and maintenance of microbial diversity.

Our findings, together with further studies on the patterns of endolithic colonisation within different lithic substrates, will provided insights into the adaptive strategies of life in extreme environments. This will set the stage for the reconstruction of historical patterns of colonisation in desert areas and for predicting future changes in microbial habitats in deserts affected by climate change. These observations are particularly relevant to the search for life on Mars, since they provide a continuum in the spectrum of possible habitats available to life on the surface of the planet as conditions changed from relatively wet to extremely cold and dry.

\section{Supplementary material related to this article is available online at: http://www.biogeosciences.net/10/ 2439/2013/bg-10-2439-2013-supplement.pdf.}

Acknowledgements. The authors thank F. Pinto and T. Carnota for technical assistance, R. Gonzalez for help with the FRX and M. Juanco with the XRD. B. Cámara and D. Herrera are thanked for field assistance in the Atacama Desert in 2010. This work was funded by grant CGL2010-16004 from the Spanish Ministry of Science and Innovation to JW, CA and OA, and by grant EXOB08-0033 from NASA and grant NSF-0918907 from the National Science foundation to JDR.

Edited by: T. Treude

\section{References}

Amaral, G., Martinez-Frias, J., and Vázquez, L.: UV shielding properties of jarosite vs. gypsum: astrobiological implications for Mars, World Appl. Sci. J., 2, 112-116, 2007.

Angiuoli, S., Matalka, M., Gussman, A., Galens, K., Vangala, M., Riley, D., Arze, C., White, J., White, O., and Fricke, W. F.: CloVR: A virtual machine for automated and portable sequence analysis from the desktop using cloud computing, BMC Bioinformatics, 12, doi:10.1186/1471-2105-12-356, 2011.

Azúa-Bustos, A., González-Silva, C., Mancilla, R. A., Salas, L., Gómez-Silva, B., McKay, C. P., and Vicuña, R.: Hypolithic Cyanobacteria Supported Mainly by Fog in the Coastal Range of the Atacama Desert, Microb. Ecol., 61, 568-581, 2011.

Büdel, B., J., B., Bicker, F. R., and Allan Green, T. G.: Dewfall As a water source frequently activates the endolithic cyanobacterial communities in the granites of Taylor Valley, Antarctica, J. Phycol., 44, 1415-1424, 2008.

Cary, S. C., McDonald, I. R., Barrett, J. E., and Cowan, D. A.: On the rocks: the microbiology of Antarctic Dry Valley soils, Nat. Rev. Microbiol., 8, 129-138, 2010.

Clarke, J. D. A.: Antiquity of aridity in the Chilean Atacama Desert, Geomorphology, 73, 101-114, 2006

Cockell, C. S. and Raven, J. A.: Zones of photosynthetic potential on Mars and the early Earth, Icarus, 169, 300-310, 2004.

Cockell, C. S., McKay, C. P., Warren-Rhodes, K., and Horneck, G.: Ultraviolet radiation-induced limitation to epilithic microbial growth in arid deserts - Dosimetric experiments in the hyperarid core of the Atacama Desert, J. Photochem. Photobiol., 90, 79-87, 2008.

Cockell, C. S., Osinski, G. R., Banerjee, N. R., Howard, K. T., Gilmour, I., and Watson, J. S.: The microbe-mineral environment and gypsum neogenesis in a weathered polar evaporite, Geobiology, 8, 293-308, 2010.

Cockell, C. S., Pybus, D., Olsson-Francis, K., Kelly, L., Petley, D., Rosser, N., Howard, K., and Mosselmans, F.: Molecular characterisation and geological microenvironment of a microbial community inhabiting weathered receding shale cliffs, Microb. Ecol., 61, 166-181, 2011.

Connon, S. A., Lester, E. D., Shafaat, H. S., Obenhuber, D. C., and Ponce, A.: Bacterial diversity in hyperarid Atacama Desert soils, J. Geophys. Res., 112, G04S17, doi:10.1029/2006JG000311, 2007.

Corbel, J.: Les karst des régions chaudes: des déserts aux zones tropicales humides, Stud. Geomorphol. Carpatho-Balcanica, 5, 49-76, 1971.

Danin, A.: Desert Rocks as Plant Refugia in the near East, Botanical Rev., 65, 93-170, 1999. 
Davila, A. F., Gomez-Silva, B., de los Rios, A., Ascaso, C., Olivares, H., McKay, C. P., and Wierzchos, J.: Facilitation of endolithic microbial survival in the hyperarid core of the Atacama Desert by mineral deliquescence, J. Geophys. Res., 113, G01028, doi:10.1029/2007JG000561, 2008.

de la Torre, J. R., Goebel, B. M., Friedmann, E. I., and Pace, N. R.: Microbial diversity of cryptoendolithic communities from the McMurdo Dry Valleys, Antarctica, Appl. Environ. Microbiol., 69, 3858-3867, 2003.

de los Rios, A., Valea, S., Ascaso, C., Davila, A. F., Kastovsky, J., McKay, C. P., Gomez-Silva, B., and Wierzchos, J.: Comparative analysis of the microbial communities inhabiting halite evaporites of the Atacama Desert, Int. Microbiol., 2, 79-89, 2010.

DeSantis, T. Z., Jr., Hugenholtz, P., Keller, K., Brodie, E. L., Larsen, N., Piceno, Y. M., Phan, R., and Andersen, G. L.: NAST: a multiple sequence alignment server for comparative analysis of $16 \mathrm{~S}$ rRNA genes, Nucl. Acids Res., 34, 394-399, 2006.

Dong, H., Rech, J. A., Jiang, H., Sun, H., and Buck, B. J.: Endolithic cyanobacteria in soil gypsum: occurrences in Atacama (Chile), Mojave (USA), and Al-Jafr Basin (Jordan) Deserts, J. Geophys. Res. , 112, G02030, doi:10.1029/2006JG000385, 2007.

Drees, K. P., Neilson, J. W., Betancourt, J. L., Quade, J., Henderson, D. A., Pryor, B. M., and Maier, R. M.: Bacterial community structure in the hyperarid core of the Atacama Desert, Chile, Appl. Environ. Microbiol., 72, 7902-7908, 2006.

Dunai, T. J., Gonzalez Lopez, G. A., and Juez-Larre, J.: OligoceneMiocene age of aridity in the Atacama Desert revealed by exposure dating of erosion-sensitive landforms, Geology, 33, 321324,2005

Friedmann, E. I.: Endolithic Microorganisms in the Antarctic Cold Desert, Science, 215, 1045-1053, 1982.

Friedmann, E. I. and Ocampo-Friedmann, R.: Endolithic microorganisms in extreme dry environments: analysis of a lithobiontic microbial habitat., in: Current Perspectives in Microbial Ecology, edited by: Klug, M. J., and Reddy, C. A., ASM Press, Washington, DC, 177-185, 1984.

Gilbert, J. A., Field, D., Swift, P., Newbold, L., Oliver, A., Smyth, T., Somerfield, P. J., Huse, S., and Joint, I.: The seasonal structure of microbial communities in the Western English Channel, Environ Microbiol, 11, 3132-3139, 2009.

Glavin, D. P., Cleaves, H. J., Schubert, M., Aubrey, A., and Bada, J. L.: New method for estimating bacterial cell abundances in natural samples by use of sublimation, Appl. Environ. Microbiol., 70, 5923-5928, 2004.

Golubic, S., Friedmann, I., and Schneider, J.: The lithobiontic ecological niche, with special reference to microorganisms, J. Sedim. Petrol., 51, 475-478, 1981.

Hartley, A. and Chong, G.: Late Pliocene age for the Atacama Desert: implications for the desertification of western South America, Geology, 30, 43-46, 2002.

Hartley, A. J., Chong, G., Houston, J., and Mather, A. E.: 150 million years of climatic stability: evidence from the Atacama Desert, northern Chile, J. Geol. Soc., 162, 421-424, 2005.

Herrera, A., Cockell, C. S., Self, S., Blaxter, M., Reitner, J., Thorsteinsson, T., Arp, G., Dröse, W., and Tindle, A. G.: A cryptoendolithic community in volcanic glass, Astrobiology, 9, 369$381,2009$.

Horath, T. and Bachofen, R.: Molecular characterisation of an endolithic microbial community in dolomite rock in the central
Alps (Switzerland), Microb. Ecol., 58, 290-306, 2009.

Horath, T., Neu, T. R., and Bachofen, R.: An endolithic microbial community in dolomite rock in central Switzerland: characterisation by reflection spectroscopy, pigment analyses, scanning electron microscopy, and laser scanning microscopy, Microb. Ecol., 51, 353-364, 2006.

Houston, J.: Evaporation in the Atacama Desert: An empirical study of spatio-temporal variations and their causes, J. Hydrology, 330, 402-412, 2006.

Houston, J. and Hartley, A. J.: The Central Andean west-slope rainshadow and its potential contribution to the origin of hyperaridity in the Atacama Desert, Int. J. Climatol. , 23, 1453-1464, 2003.

Hughes, K. A. and Lawley, B.: A novel Antarctic microbial endolithic community within gypsum crusts, Environ. Microbiol., 7, 555-565, 2003.

Kappen, L., Lange, O. L., Schulze, E.-D., and Evenari, M.: Ecophysiological investigations on lichens of the Negev Desert, VI. Annual course of the photosynthetic production, Flora, 168, 85108, 1979.

Kidron, G. J.: Altitude dependent dew and fog in the Negev Desert, Israel, Agri Forest Meteorol, 96, 1-8, 1999.

Kidron, G. J.: Analysis of dew precipitation in three habitats within a small arid drainage basin, Negev Highlands, Israel, Atmosph Res., 55, 257-270, 2000.

Kuhlman, K. R., Enkat, P., La Duc, M. T., Kuhlman, G. M., and McKay, C. P.: Evidence of a microbial community associated with rock varnish at Yungay, Atacama Desert, Chile, J. Geophys. Res., 113, G04022, doi:10.1029/2007JG000677, 2008.

Lane, D. J.: 16S/23S rRNA sequencing, in: In Nucleic acid techniques in bacterial systematics, edited by: Stackebrandt, E., and Goodfellow, M., John Wiley and Sons, New York, 115-175, 1991.

Laudermilk, J. D. and Woodford, A. O.: Concerning rillensteine, Am. J. Sci., 23, 135-154, 1932.

Lebas, M. J., Lemaitre, R. W., Streckeisen, A., and Zanettin, B.: A chemical classification of volcanic-rocks based on the total alkali silica diagram, J. Petrol, 27, 745-750, 1986.

Lester, E. D., Satomi, M., and Ponce, A.: Microflora of extreme arid Atacama Desert Soils, Soil Biol. Biochem., 39, 704-708, 2007.

Ley, R. E., Harris, J. K., Wilcox, J., Spear, J. R., Miller, S. R., Bebout, B. M., Maresca, J. A., Bryant, D. A., Sogin, M. L., and Pace, N. R.: Unexpected diversity and complexity of the Guerrero Negro hypersaline microbial mat, Appl. Environ. Microbiol., 72, 3685-3695, 2006.

Lozupone, C., Hamady, M., and Knight, R.: UniFrac-an online tool for comparing microbial community diversity in a phylogenetic context, BMC Bioinformatics, 7, doi:10.1186/1471-2105-7-371, 2006.

Lozupone, C., Lladser, M. E., Knights, D., Stombaugh, J., and Knight, R.: UniFrac: an effective distance metric for microbial community comparison, ISME J., 5, 169-172, 2011.

Maier, R. M., Drees, K. P., Neilson, J. W., Henderson, D. A., Quade, J., and Betancourt, J. L.: Microbial life in the Atacama Desert, Science, 302, 1018-1021, 2003.

Matthes, U., Turner, S. J., and Larson, D. W.: Light Attenuation by Limestone Rock and Its Constraint on the Depth Distribution of Endolithic Algae and Cyanobacteria, Int. J. Plant. Sci., 162, 263-270, 2001. 
McKay, C. P., Friedmann, E. I., Gomez-Silva, B., CaceresVillanueva, L., Andersen, D. T., and Landheim, R.: Temperature and moisture conditions for life in the extreme arid region of the Atacama desert: four years of observations including the El Nino of 1997-1998, Astrobiology, 3, 393-406, 2003.

Miller, A.: The climate of Chile, in: Climates of Central and South America, edited by: Schwerdtfeger, R., Elsevier Scientific Publishing Company, Amsterdam, 113-145, 1976.

Navarro-Gonzalez, R., Rainey, F. A., Molina, P., Bagaley, D. R., Hollen, B. J., de la Rosa, J., Small, A. M., Quinn, R. C., Grunthaner, F. J., Caceres, L., Gomez-Silva, B., and McKay, C. P.: Mars-like soils in the Atacama Desert, Chile, and the dry limit of microbial life, Science, 302, 1018-1021, 2003.

Nienow, J. A.: Extremophiles: Dry Environments (including Cryptoendoliths), in: Encyclopedia of Microbiology, Elsevier, Oxford, 159-173, 2009.

Ohba, T. and Nakagawa, H.: Minerals in volcanic ash 2: nonmagmatic minerals, Global Environ. Res., 6, 53-59, 2002.

Omelon, C. R.: Endolithic microbial communities in polar desert habitats, Geomicrobiol. J., 25, 404-414, 2008.

Petrash, D. A., Gingras, M. K., Lalonde, S. V., Orange, F., Pecoits, E., and Konhauser, O.: Dynamic controls on accretion and lithification of modern gypsum-dominated thrombolites, Los Rogues, Venezuela, Sediment. Geol., 245, 29-47, 2012.

Phoenix, V. R., Bennett, P. C., Engel, A. S., Tyler, S. W., and Ferris, F. G.: Chilean high-altitude hot-spring sinters: a model system for UV screening mechanisms by early Precambrian cyanobacteria, Geobiology, 4 15-28, 2006.

Pointing, S. B., Chan, Y., Lacap, D. C., Lau, M. C., Jurgens, J. A., and Farrell, R. L.: Highly specialized microbial diversity in hyper-arid polar desert, Proc. Natl. Acad. Sci. USA, 106, 1996419969, 2009.

Schloss, P. D., Westcott, S. L., Ryabin, T., Hall, J. R., Hartmann, M., Hollister, E. B., Lesniewski, R. A., Oakley, B. B., Parks, D. H., Robinson, C. J., Sahl, J. W., Stres, B., Thallinger, G. G., Van Horn, D. J., and Weber, C. F.: Introducing mothur: open-source, platform-independent, community-supported software for describing and comparing microbial communities, Appl. Environ. Microbiol., 75, 7537-7541, 2009.

Smith, B. J.: Weathering of superficial limestone debris in a hot desert environment, Geomorphology, 1, 355-367, 1988.

Smith, B. J., Warke, P. A., and Moses, C. M.: Limestone weathering in a contemporary arid environment: A case study from southern Tunisia, Earth Surf. Proc. Land, 25, 1343-1354, 2000.

Sogin, M. L., Morrison, H. G., Huber, J. A., Welch, D. M., Huse, S. M., Neal, P. R., Arrieta, J. M., and Herndl, G. J.: Microbial diversity in the deep sea and the underexplored "rare biosphere", Proc. Natl. Acad. Sci. USA, 103, 12115-12120, 2006.

Vítek, P., Cámara-Gallego, B., Edwards, H. G. M., Jehlička, J., Ascaso, C., and Wierzchos, J.: Phototrophic community in gypsum crust from the Atacama Desert studied by Raman spectroscopy and microscopic imaging, Geomicrobiol. J., 30, 1-12, 2013.
Walker, J. J. and Pace, N. R.: Endolithic microbial ecosystems, Annu. Rev. Microbiol., 61, 331-347, 2007a.

Walker, J. J. and Pace, N. R.: Phylogenetic composition of Rocky Mountain endolithic microbial ecosystems, Appl. Environ. Microbiol., 73, 3497-3504, 2007b.

Warren-Rhodes, K. A., Rhodes, K. L., Pointing, S. B., Ewing, S. A., Lacap, D. C., Gomez-Silva, B., Amundson, R., Friedmann, E. I., and McKay, C. P.: Hypolithic cyanobacteria, dry limit of photosynthesis, and microbial ecology in the hyperarid Atacama Desert, Microb. Ecol., 52, 389-398, 2006.

Warren-Rhodes, K., Dungan, J., Piatek, J., and McKay, C.: Ecology and spatial pattern of cyanobacterial community island patches in the Atacama Desert, J. Geophys. Res., 112, G04S15, doi:10.1029/2006JG000305, 2007.

Wierzchos, J. and Ascaso, C.: Application of backscattered electron imaging to the study of the lichen-rock interface, J. Microsc., 175, 54-59, 1994.

Wierzchos, J., Ascaso, C., and McKay, C. P.: Endolithic cyanobacteria in halite rocks from the hyperarid core of the Atacama Desert, Astrobiology, 6, 415-422, 2006a.

Wierzchos, J., Berlanga, M., Ascaso, C., and Guerrero, R.: Micromorphological characterisation and lithification of microbial mats from the Ebro Delta (Spain), Int. Microbiol., 9, 289-295, 2006 b.

Wierzchos, J., Camara, B., de Los Rios, A., Davila, A. F., Sanchez Almazo, I. M., Artieda, O., Wierzchos, K., Gomez-Silva, B., McKay, C., and Ascaso, C.: Microbial colonisation of Ca-sulfate crusts in the hyperarid core of the Atacama Desert: implications for the search for life on Mars, Geobiology, 9, 44-60, 2011.

Wierzchos, J., Davila, A. F., Artieda, O., Cámara, B., de los Ríos, A., Nealson, K. H., Valea, S., Garcia-Gónzalez, M. T., and Ascaso, C.: Ignimbrite as a substrate for endolithic life in the hyperarid Atacama Desert: implications for the search for life on Mars, Icarus, doi:10.1016/j.icarus.2012.06.009, 2012a.

Wierzchos, J., Davila, A. F., Sánchez-Almazo, I. M., Hajnos, M., Swieboda, R., and Ascaso, C.: Novel water source for endolithic life in the hyperarid core of the Atacama Desert, Biogeosciences, 9, 2275-2286, doi:10.5194/bg-9-2275-2012, 2012b.

Wierzchos, J., de Los Rios, A., and Ascaso, C.: Microorganisms in desert rocks: the edge of life in Earth, Inter. Rev., 15, 171-181, 2012c.

Wong, F. K., Lau, M. C., Lacap, D. C., Aitchison, J. C., Cowan, D. A., and Pointing, S. B.: Endolithic microbial colonisation of limestone in a high-altitude arid environment, Microb. Ecol., 59, 689-699, 2010.

Yue, J. C. and Clayton, M. K.: A similarity measure based on species proportions, Commun. Stat. Theor. M., 34, 2123-2131, 2006. 